\title{
APLICABILIDADE E EFICÁCIA DAS AÇÕES CONSTITUCIONAIS.
}

\section{APPLICABILITY AND EFFECTIVENESS OF CONSTITUTIONAL ACTIONS.}

\section{Emerson Barrack Cavalcanti}

Bacharel em Direito. Pós-Graduado em Direito Público e Privado Fundação Faculdade Presidente Antônio Carlos de Teófilo Otoni/MG, Brasil

E-mail: cavalcanti.ebc@gmail.com

Recebido: 01/05/2020 - Aceito: 20/05/2020

\section{Resumo}

Estuda-se aqui a aplicabilidade e a eficácia das ações constitucionais. Com isto, o principal objetivo deste Artigo será analisar a aplicabilidade das ações constitucionais, delimitando a eficácia de cada uma delas para a manutenção do pleno Estado de Direito no Brasil. Com esta tarefa realizada, será possível avaliar até que ponto os instrumentos normativos estabelecidos pela Carta Magna de 1988 são úteis para o fomento da cidadania ampla e irrestrita, em todas as ocasiões e contextos. Aproveitando-se da abordagem qualitativa, executou-se aqui uma revisão dos principais conceitos, definições, ideias, paradigmas, premissas e teorias úteis ao executar pleno deste estudo. Conquanto seja uma meta bastante complexa, o intuito básico de qualquer constituição é possibilitar a manutenção do pleno estado direito. Isto irá se efetivar mediante uma revisão de natureza qualitativa que sintetizará os posicionamentos jurisprudenciais e doutrinários que delimitam as suas mais relevantes premissas, destacando-se as indispensáveis à manutenção do estado de direito no Brasil. Em suma, estas são as principais ideias exploradas neste Artigo.

Palavras-chave: Ações; Constitucionais; Direito; Eficácia; Brasil..

\section{Abstract}

The applicability and effectiveness of constitutional actions are studied here. With this, the main objective of this Article will be to analyze the applicability of constitutional actions, delimiting the effectiveness of each one of them for the maintenance of the full rule of law in Brazil. With this task accomplished, it will be possible to evaluate the extent to which the normative instruments established by the 1988 Constitution are useful for the promotion of broad and unrestricted citizenship, in all occasions and contexts. Taking advantage of the qualitative approach, a review of the main concepts, definitions, ideas, paradigms, premises, and theories useful when carrying out this study was performed. While it is a rather complex goal, the basic purpose of any constitution is to make it possible to maintain the full right state. This will become effective through a qualitative review that summarizes the jurisprudential and doctrinal positions that delimit its most relevant premises, highlighting those that are essential to the maintenance of the rule of law in Brazil. In short, these are the main ideas explored 
in this Article.

Keywords: Actions; Constitutional; Right; Efficirncy; Brazil.

\section{Introdução}

Neste Artigo, estudar-se-á a aplicabilidade e a eficácia das ações constitucionais. Isto irá se efetivar mediante uma revisão de natureza qualitativa que sintetizará os posicionamentos jurisprudenciais e doutrinários que delimitam as suas mais relevantes premissas, destacando-se as indispensáveis à manutenção do estado de direito no Brasil.

Conquanto seja uma meta bastante complexa, o intuito básico de qualquer constituição é possibilitar a manutenção do pleno Estado de Direito ${ }^{1}$. Para que isto aconteça, urge que sejam salvaguardados direito e deveres em igual medida pelo efetivar prático de uma quantidade mais ou menos variável de premissas adequadas ao saudável convívio social².

Isto tudo só se tornará possível pela criação e a subsequente manutenção de um clima institucional direcionado ao interesse coletivo, preservando tudo que lhe seja favorável, apesar dos desafios que the permeiam³ ${ }^{3}$.

Por isto, a aplicabilidade e a eficácia das ações constitucionais, quando justamente observadas, implicam no custeio apropriado do estado de direito que se espera em uma sociedade igualitária e justa 4 .

Aliás, o ideal é que isto seja consumado de uma só vez com igual eficácia e qualidade, mesmo que incite em uma grande quantidade de desafios institucionais em paralelo 5 .

Desta maneira, o problema de pesquisa se sumaria na seguinte indagação: Até que ponto as ações constitucionais expressas na Carta Magna de 1988 são eficazes para a manutenção do pleno Estado de Direito no Brasil? Para respondê-la, são consumadas todas as tarefas subsequentes deste estudo aproveitando-se da abordagem metodológica descrita adiante.

Nesta perspectiva, o principal objetivo deste Artigo será analisar a aplicabilidade das ações constitucionais, delimitando a eficácia de cada uma delas para a manutenção do pleno Estado de Direito no Brasil.

Com esta tarefa realizada, será possível avaliar até que ponto os instrumentos normativos estabelecidos pela Carta Magna de 1988 são úteis para o fomento da

\footnotetext{
${ }^{1}$ Rodrigues (2016).

2 Sarlet (2018).

${ }^{3}$ Streck (2019).

${ }^{4}$ Branco \& Mendes (2019).
} 
cidadania ampla e irrestrita, em todas as ocasiões e contextos. Como complemento, também serão executados dois objetivos específicos.

No primeiro deles, a meta será apontar de forma descritiva as principais ações constitucionais prescritas na Carta Magna de 1988.

Mais adiante, o desígnio será correlacionar a eficácia destas ações para construção da cidadania pelo equilíbrio de direitos e deveres.

A priori, a realização deste estudo contribuirá para a construção e o custeio de um Estado de Direito consonante à preservação plena da cidadania ${ }^{6}$.

Ao se descrever as principais ações constitucionais prescritas na Carta Magna de 1988, será possível correlacionar a construção da cidadania pelo equilíbrio de direitos e deveres pelas premissas do direito pátrio7. Com estas duas tarefas executadas, viabiliza-se, o vislumbre sistemático da base normativa brasileira que se destina ao preservar qualificado de todos os direitos e deveres civis, consolidando o estado de direito atual ${ }^{8}$.

Evidentemente, as premissas constitucionais de 1988 não estão além e nem aquém do que delas se espera, desde que aplicadas em prol da defesa sistemática da cidadania 9 . Por consequência, este estudo poderá auxiliar em dimensionar a aplicabilidade e a eficácia das ações constitucionais, salvaguardando a manutenção do pleno Estado de Direito no Brasil ${ }^{10}$.

Como já dito acima, este Artigo se realizará aproveitando-se da abordagem qualitativa para que uma revisão dos principais conceitos, definições, ideias, paradigmas, premissas e teorias; se realize com eficácia.

Pela abordagem qualitativa, é possível explorar as principais particularidades do tema investigado mediante o uso do método teórico indutivo, esmiuçando de forma plena as particularidades mais relevantes da problemática que Ihe fundamenta ${ }^{11}$. Isto tudo irá se suceder pelo uso de fontes de natureza escrita, incluindo-se a Carta Magna de 1988, além de artigos, dissertações, teses e livros úteis ao realizar sistemático de todos os objetivos de pesquisa ${ }^{12}$.

Usando esta metodologia, possibilitar-se-á apontar, avaliar e compreender as principais premissas que embasam o tema que aqui se investiga, equacionando o problema de pesquisa de forma clara, direta e precisa mais adiante ${ }^{13}$.

Em suma, estas são as principais ideias que serão exploradas neste Artigo.

\footnotetext{
${ }^{5}$ Barroso (2019).

${ }^{6}$ Vasconcelos (2018).

${ }^{7}$ Bresser-Pereira (2018).

8 Oliveira (2017).

${ }^{9}$ Reschke (2017).

${ }^{10}$ Dezan (2016).

${ }^{11}$ Ehrhardt Júnior (2018).

12 Barbosa (2010; 2016).

${ }^{13}$ Lakatos \& Marconi $(2007 ; 2010)$.
} 
Espera-se que os seus resultados sejam úteis ao estudo da problemática que lhe permeia, contribuindo ao debate que lhe fundamenta.

\section{As Ações Constitucionais}

No âmbito do direito pátrio, considera-se como ações constitucionais, todos os instrumentos normativos que visam salvaguardar a aplicação justa da lei. Como tal, podem ser vistos como prováveis remédios normativos que estão à disposição dos operadores do direito em prol da prática eficaz da justiça, preservando-se deveres e direitos em igual medida (BRANCO; MENDES, 2019).

No momento, o direito pátrio dispõe de 6 (seis) ações constitucionais distintas. Ao lado dos Mandados de Segurança e de Injunção, também há os Habeas Corpus e Data, além da Ação Popular e a Civil Pública.

Tanto na Carta Magna de 1988 como na Lei 12.016/2009, considera-se como Mandado de Segurança o remédio constitucional que visa defender todos os direitos líquidos e certos do cidadão. Na prática, estes direitos se salvaguardam mediante o uso deste instrumento, ou seja, do mandado de segurança, quando os habeas corpus e o habeas data são insuficientes para esta tarefa. Aliás, como direito líquido e certo se vislumbra toda e qualquer prerrogativa normativa de salvaguarda que é expressa de forma clara, direta e precisa em uma lei própria (BARROSO, 2019).

Isto significa que, se líquido e certo, pode ser experimentado de imediato, livre de qualquer controvérsia, porquanto as suas implicações são diretas e objetivas.

Por sua vez, considera-se como Mandado de Injunção o remédio constitucional que possibilita ao Supremo Tribunal Federal (STF) avisar o poder legislativo sobre a provável ausência de uma norma específica que se faça necessária a salvaguarda da cidadania, da nacionalidade e da soberania.

Por consequência, a sua meta, conforme se vislumbra no Artigo $5^{\circ}$, Inciso LXXI da Carta Magna de 1988, é dar azo o emergir de uma medida que possa servir como ponto de partida para uma necessária correção no âmbito do ordenamento pátrio, corrigindo uma provável falha reguladora (BRESSER-PEREIRA, 2018).

Nesta perspectiva, o seu uso só se justifica pela omissão inequívoca das leis sobre qualquer tema que diz respeito a preservação da soberania, da nacionalidade e da cidadania, como já descrito acima.

Em todas as ocasiões e contextos, o Habeas Corpus visa preservar o experimento da liberdade de locomoção de um indivíduo preso ou ameaçado de ser preso por alguma autoridade. Este amparo é passível de lhe ser concedido quando comprovada qualquer agressão do Estado que possa afetar o seu direito de ir e vir, se comprovada a sua ilegalidade bem como o abuso de poder dos agentes estatais em paralelo. 
Por consequência, o ensejo deste remédio constitucional é impedir que a coação ilegal da liberdade do cidadão, ao constranger qualquer ato violento que se destine a cerceá-lo ausentando-se uma motivação realmente justa (FERRAZ; VASCONCELLOS, 2013; STRECK, 2019). Por conta dos seus resultados, é uma das ações constitucionais mais importantes para a preservação qualificada do pleno estado de direito.

Por sua vez, o Habeas Data tem como meta a garantia do acesso à informação ao cidadão. Para tanto, Ihe concedidos os meios legais que implicam no acesso com qualidade de todos os dados que the interessam, desde que sejam respeitados os trâmites legais para tanto e que não exista nenhum impedimento legal. Talvez não pareça de imediato, mas a possibilidade de acessar e usufruir informações, ao lado da liberdade de se locomover, é uma premissa indispensável à preservação plena do estado de direito.

Quando uma sociedade não tem direito de conhecer tudo que the interessa ou que lhe diz respeito, sobretudo dados e informações que se encontram, em posse do Estado, a manutenção do interesse coletivo se encontra gravemente ameaçada (GIACOBBO; HERMANY, 2016; STRECK, 2019). Por isto o habeas data é tão importante o Habeas Corpus para o custeio apropriado do moderno Estado de Direito.

Visando defender a moralidade administrativa e o meio ambiente, além dos patrimônios histórico e cultural, a ação popular é o remédio que concede ao cidadão a prerrogativa de se mover judicialmente em defesa dos direitos coletivos.

No âmbito do direito pátrio, esta ação constitucional é apresentada nas premissas constitucionais desde a constituição de 1824, ausentando-se apenas na primeira carta magna da era republicana, isto é, da constituição de 1891, além das constituições de 1937 e 1969. No momento, as ações populares se destacam como uma das ferramentas normativas mais importantes para a defesa do direito coletivo, visto que o seu uso implica na preservação qualificada do estado de direito (MARINONI; MITIDIERO; SARLET, 2019; OLIVEIRA, 2017). Se bem aplicada, os atos lesivos do Estado poderão ser coibidos com eficácia.

Ao seu turno, a Ação Civil Pública é o instrumento processual disponível ao Ministério Público (MP) e para outras entidades legitimadas para que se suceda a defesa dos direitos coletivos, difusos, homogêneos e individuais. Aliás, o uso deste remédio não se destina à salvaguarda de direitos privados e nem a defesa dos interesses disponíveis ao cidadão de forma única e exclusiva, mas para as categorias e os grupos sociais que aglutinam interesses em comum (RODRIGUES, 2016).

Estes interesses estão, portanto, passíveis de uma defesa qualificada mediante a intervenção de órgãos, entre os quais se destaca o MP, que vão agir no sentido de preservá-los conforme se cogita no ordenamento pátrio. 
Em suma, uso sistemático de todas estas ações ou remédios possibilitará a preservação do Estado de Direito correspondente à defesa da cidadania.

Evidentemente, isto só acontece porque o intuito deles é fomentar o emergir de ambiente normativo igualitário e justo, combatendo todo e qualquer abuso contrário ao bem do povo (SARLET, 2018). Não é à toa que a Carta Magna de 1988 os determina, estabelecendo as premissas que irão orientá-los.

\section{Dimensionando a Eficácia das Ações Constitucionais}

Dimensionando-se a eficácia das ações constitucionais, será possível compreender porque os remédios constitucionais são tão importantes para a manutenção do Estado de Direito vigente no momento (MARMELSTEIN, 2015; PEREIRA, 2009).

Para isso, é preciso compreender quais são as consequências que se vinculam ao uso sistematizado de todas as ações constitucionais. Isto por este caminho será viável compreender de que forma as premissas expressas na Carta Magna de 1988 são relevantes para a preservação da democracia na prática, fomentando a manifestação absoluta da cidadania (KUNRATH, 2016).

\subsection{Mandado de Segurança}

Detalhado com maior precisão na Lei 12.016/2009, o Mandado de Segurança, ao se destinar a defesa de direito líquido e certo, é indispensável a salvaguarda de direitos inequívocos, além de expressamente detalhados no ordenamento pátrio.

Se detalhados, são válidos e merecem toda e qualquer salvaguarda destinada a preservá-lo, concedendo a sociedade a indispensável segurança jurídica.

Nesta perspectiva, constata-se que esse remédio constitucional implica na salvaguarda de direitos e deveres. Isto, aliás, irá se suceder quando equalizados com eficácia em prol do experimento da cidadania ampla e irrestrita que se resguarda pelo uso do Mandado de Segurança (VASCONCELOS, 2018). Evidentemente, isto só irá acontecer se este remédio constitucional for aplicado evidenciando-se os seus pontos fortes, ao explorá-lo onde se aplica com precisão.

Para que o Mandado de Segurança seja aplicado conforme se cogita, é preciso que realmente exista uma ameaça real para um direito inequivocamente certo e líquido. Quando o direito líquido e certo é ameaçado pelos agentes estatais, constatase uma prática ilegal ou até o patente abuso de poder que solicita rápida e precisa correção. 
Nas duas situações, urge que sejam aplicadas correções que sejam destinadas à defesa qualificada do direito. Isto significa que lhe serão concedidos ao cidadão todos os meios de salvaguardá-lo do excesso de poder ou de qualquer ato ilícito que irá prejudicá-lo, impedindo que ele seja injustamente limitado (EHRHARDT JÚNIOR, 2018; LIMA, 2016).

Sendo assim, verifica-se que o uso sistematizado do Mandado de Segurança é de suma importância para a construção da cidadania pela salvaguarda de todos os direitos e deveres expressos no ordenamento pátrio como um todo.

\subsection{Mandado de Injunção}

Um dos maiores desafios para que a máquina pública cumpra com qualidade as suas atribuições é executar tudo com a necessária celeridade em um só tempo. Perante a lentidão quase patológica da máquina pública, não é à toa a sensação generalizada de baixa qualidade no experimento dos serviços da justiça oferecidos à população como um todo. Um remédio constitucional que tem como função qualificar as decisões da justiça, inclusive mediante a máxima celeridade possível, se vislumbra no Mandado de Injunção.

Para tudo isto, ele pode ser proposto por qualquer cidadão que busca salvaguardar as liberdades e direitos constitucionais correlacionados à nacionalidade e a soberania (BRAZ, 2016). O mandado de injunção é, portanto, fundamental para a defesa da cidadania.

Enquanto o Mandado de Segurança vise defender direito líquido e certo, o Mandado de Injunção tenciona salvaguardar o interesse coletivo. Isto irá quando se constata a ausência de um provável decreto, lei, norma ou regulamento sobre uma determinada demanda em particular. Ou seja, na ausência de determinação normativa própria, sobretudo para toda e qualquer matéria adequada ao experimento apropriado da cidadania, este instrumento tenciona preservar os direitos constitucionais e as liberdades concedidas aos cidadãos. Com esta meta em pauta, constata-se que a sua serventia à manutenção eficaz do moderno estado de direito é absoluta, além de inquestionável no momento, contribuindo bastante para aquilo que ao coletivo diz respeito (RESCHKE, 2017).

Como um instituto legítimo, ele deve ser usado quando necessário for, principalmente se este isto for favorável ao povo, defendendo-o por conta da ausência de norma própria em alguns litígios.

\subsection{Habeas Corpus}


Em qualquer sociedade, a liberdade plena e absoluta para ir e vir a qualquer lugar, quando muito bem entender, é uma premissa indispensável para que a paz e a concórdia sejam experimentadas em absoluto. Isto significa que, se a liberdade de se locomover é cerceada, mesmo que isto se suceda de forma indireta, perpetra-se uma grave afronta não apenas ao direito privado, mas a própria sociedade como um todo (DEZAN, 2016).

Para que nada disto aconteça, existe o Habeas Corpus, um dos remédios constitucionais mais importantes aos anseios do povo, os quais clamam por justiça em todas as ocasiões. Justiça que jamais existirá ausentando a liberdade natural de se locomover.

Considerando as contribuições para que o direito de locomoção seja plenamente experimentado, desde que isto não implique em grave afronta ao direito alheio, o Habeas Corpus é indispensável à defesa qualificada do estado de direito.

Evidentemente, em absoluto e sem restrições, ou seja, sem alguns freios e limitações, liberdade nenhuma é plausível de se experimentar em qualquer sociedade, pois a vida em coletivo implica em abrir mão de algumas vontades individuais. Isto se efetiva com o intuito de se possibilitar a manutenção da paz e da concórdia, reforçando ao máximo o direito coletivo, determinando que ele é a base para que os conflitos sociais sejam evitados (MARMELSTEIN, 2015; OLIVEIRA, 2017).

Por tudo isto, verifica-se que a utilidade do Habeas Corpus para que a sociedade brasileira lide melhor com as suas próprias dificuldades é inquestionável, principalmente quando o Estado cerceia sem justificativas a liberdade individual. Afinal é impossível existir cidadania ampla e irrestrita sem liberdade.

\subsection{Habeas Data}

O sincretismo bem como o uso excessivo do segredo em tudo para todos a qualquer custo não é algo que se alinha com a manutenção da democracia. Se impossível é custear o Estado Democrático, dificultando-se o acesso à informação, inviável também será preservar o experimento da cidadania. Ou seja, é impraticável que a cidadania realmente seja ampla e irrestrita, pelo experimento qualificado de direitos e deveres, se as pessoas estão impossibilitadas de acessar as informações que precisa.

Nestas condições, transforma-se a democracia em uma mera falácia verborrágica, de tal maneira que a cidadania não passa tão somente de um anátema linguístico (VASCONCELOS, 2018). Como tal, expressa algo irreal, servindo só para aplacar a vontade popular. 
Devido à segurança nacional, além do custeio do segredo de justiça, muitas informações que o Estado tem sobre qualquer pessoa deverão receber o indispensável acolhimento. Tão somente isto é um motivo válido para que o acesso às informações em órgãos públicos seja restringido ao máximo, atrapalhando bastante o desejável conhecimento que algumas pessoas clamam por experimentar.

Inclusive não interessa, quais sejam as suas respectivas motivações, se válidas, é fundamental que seja concedido a qualquer cidadão o direito pleno de acessar qualquer dado ou informação que lhe diz respeito (EHRHARDT JÚNIOR, 2018).

A preservação deste direito é, conquanto existam limitações para que se suceda como tal, fundamental para que o estado de direito vigente adeque-se às premissas democráticas que incitam o experimento qualificado da cidadania.

\subsection{Ação Popular}

Como qualquer cidadão é livre para questionar sobre qualquer tema que lhe fundamenta, a Ação Popular é um dos remédios constitucionais mais importantes para a defesa do estado de direito.

Sendo assim, a defesa do patrimônio histórico e cultural bem como combate a qualquer ato lesivo à moralidade administrativa, além da preservação patrimônio público, são temas plausíveis explorando-se as premissas que fundamentam este instrumento (DEZAN, 2016; RESCHKE, 2017).

Na prática, todavia, isto só é possível orientando-a para a defesa qualificada de tudo aquilo que relevante seja para a sociedade como um todo, primando em salvaguardá-la na medida do possível.

Por conta das premissas que lhe fundamenta, além dos temas que lhe são possíveis, a Ação Popular é uma ferramenta institucional útil para vigiar os atos executados pelos agentes estatais. Esta vigilância é uma de suma importância não apenas para a defesa dos interesses privativos da pessoa, se ameaçada pelos abusos e desleixos do Estado, mas para a proteção apropriada da população como um todo.

Espera-se, portanto, que o instituto da Ação Popular seja valorizado ainda mais no Brasil, porquanto as suas contribuições diretas para o experimento da democracia são inquestionáveis.

Não bastará, evidentemente, apenas acioná-la para que todas as dificuldades brasileiras sejam resolvidas ou pelo menos abrandadas ao máximo (EHRHARDT JúNIOR, 2018). 
Tomando-se ciência disto, a ação popular poderá se transformar em uma das ferramentas mais importantes para a defesa da cidadania mediante a defesa sistemática do Estado de direito.

\subsection{Ação Civil Pública}

Fundamental à defesa qualificada de todo e quaisquer interesses coletivos, difusos, individuais e homogêneos, a Ação Civil Pública é um dos instrumentos mais importantes para a salvaguarda do estado direito vigente no Brasil.

Este instrumento é tão importante para a preservação da cidadania porque se concentra sobre os direitos meta-individuais visando preservar o interesse coletivo em paralelo, sobretudo observando-se as premissas normativas os quais consolidam o direito pátrio (KUNRATH, 2016).

Se bem fundamentada, o uso da Ação Civil Pública implica na defesa qualificada do Estado de Direito, pois os seus resultados são úteis ao amparo dos interesses sociais em subsequência.

Para que isto aconteça, urge que as autoridades estatais facilitem o fluir paulatino deste instituto, porquanto ele é uma ferramenta que poderá aplacar os anseios sociais, dando uma maior sensação de justiça e segurança.

Em todas as ocasiões, todavia, é importante que sejam explorados os resultados desejados neste instrumento tomando como base a preservação de um ambiente social pacificado, porquanto nele os atos da justiça se efetivam com equidade absoluta (BRAZ, 2016).

$\mathrm{Na}$ prática, tal resultado não é tão simples, mas é uma probabilidade viável, conquanto existam os meios necessários à preservação dos interesses sociais, aplacando-se os anseios populares observando o que lei realmente visa.

\section{Considerações Finais}

Mediante uma revisão qualitativa, foi estudado aqui a aplicabilidade e a eficácia das ações constitucionais. Como tal, foi preciso enfatizar as principais posições jurisprudenciais e doutrinárias que lhe embasam, apontando até que ponto as suas principais consequências são favoráveis à manutenção do Estado de Direito atual.

Nessa perspectiva, o principal objetivo deste Artigo foi analisar a aplicabilidade das ações constitucionais, delimitando a eficácia de cada uma delas para a manutenção do pleno estado de direito no Brasil. 
Esta tarefa implicou na realização de duas outras que se destinam a complementá-la. Sendo assim, em um primeiro momento, buscou-se apontar de forma descritiva as principais ações constitucionais prescritas na Carta Magna de 1988.

Adiante, o intuito foi correlacionar a eficácia destas ações para construção da cidadania pelo equilíbrio de direitos e deveres. Ao cumprir estas ações, foi viável dimensionar a relevância dos instrumentos normativos determinados pela constituição de 1988 os quais são apontados como indispensáveis ao fomento sistemático da cidadania no Brasil. inclusive é possível afirmar que pelo experimento qualificado das premissas expostas na atual Carta Magna o que se deseja para cidadão brasileiro é que ele tenha em todas as ocasiões e contextos o experimento amplo e irrestrito de todos os seus direitos e deveres. Caso isto aconteça, certamente a vida em sociedade se sucederá com maior concórdia ou pelo menos disto se aproximando com maior frequência.

Considerando-se tudo isso, indaga-se mais uma vez: Até que ponto as ações constitucionais expressas na Carta Magna de 1988 são eficazes para a manutenção do pleno estado de direito no Brasil?

Perante os resultados que possibilitam, constata-se que as ações constitucionais que se encontram expressas na constituição de 1988 são de suma importância para que o cidadão brasileiro possa experimentar todos os seus direitos e deveres com eficácia. Isto, evidentemente, significa que não se façam necessários prováveis reforços bem como constantes intervenções para valorizá-las, com intuito de coibir prováveis abusos por parte do ente estatal, ou seja, dos seus agentes. Tal constatação, aliás, é apenas um indicativo do quanto a democracia é carente da efetiva participação social de todos os cidadãos para que os seus mecanismos não sejam deturpados.

Quando a democracia é ameaçada pelo depravar mais ou menos consistente dos elementos que são úteis em preservá-la, é preciso que a sociedade se mova para defendê-la de imediato. Se o cidadão simplesmente ignora a sua relevância para a manutenção eficaz da democracia, ele estará entregando, sem nenhuma resistência, todos os seus direitos para que Ihe usurpa, de cara deslavada. Nesta perspectiva, ele estará se transformando em anômalo escravizado pelo sistema de poder que lhe cerceia das mais variadas maneiras.

Cada uma das ações constitucionais poderá contribuir à sua maneira para a salvaguarda do pleno Estado de Direito no Brasil, contribuindo para a qualificação do experimento diário da cidadania.

Como cada uma delas também implica na justa aplicação das leis, todas as ações constitucionais também são úteis para que o Estado seja pleno na defesa do direito coletivo. Isto se efetiva quando os seus representantes, ou seja, todos os 
agentes estatais, concentram-se impedir os abusos, além de todos os atritos e escaramuças possíveis.

Por consequência, não é à toa que lado dos Mandados de Segurança e de Injunção bem como dos Habeas Corpus e Data, além da Ação Popular e a Civil Pública, se efetivam instrumentos normativos que tendem a prática eficaz da justiça, preservando-se deveres e direitos em igual medida.

Todos estes mecanismos estão ao inteiro dispor dos operadores do direito os quais deles poderão se aproveitar para a salvaguarda qualificada do pleno estado de direito no Brasil, em todas as ocasiões.

Caso a justiça brasileira se efetive sem que sejam exploradas as prováveis consequências das ações constitucionais, a tendência é que a sociedade brasileira seja arrastada para a implacável tirania.

Por isto, é fundamental valorizar o uso sistemático das ações constitucionais, inclusive relacionando-as com a defesa da democracia pela prática da cidadania ampla e irrestrita.

Em suma, estes são os resultados derradeiros do estudo.

Perante as suas prováveis limitações, espera-se que sejam pelo menos úteis à defesa da cidadania mediante o experimento qualificado das ações constitucionais.

\section{Referências}

BARBOSA, Flávio Alves. Descomplicando o Complicado: Aprendendo a Fazer Uma Monografia em Três Dias. Rio de Janeiro: Editora Ciência Moderna, 2010.

. Descomplica Monografia. Rio de Janeiro: Editora Ciência Moderna, 2016.

BARROSO, Luís Roberto. Curso de Direito Constitucional Contemporâneo. 8ª Ed. São Paulo: Saraiva, 2019.

BRANCO, Paulo Gonet; MENDES, Gilmar Ferreira. Curso de Direito Constitucional. 14ª Ed. São Paulo: Saraiva, 2019.

BRAZ, Kalini Vasconcelos. A Aplicabilidade do Princípio da Proibição do

Retrocesso Social como Meio de Garantia Constitucional ao Direito à Saúde. Rio de Janeiro: Fio Cruz, 2016. Disponível em: <http://abre.ai/aM58>. Acessado em: 15 de fevereiro de 2020.

BRESSER-PEREIRA, Luiz Carlos. Construindo o Estado Republicano: Democracia e Reforma da Gestão Pública. 2ª Ed. São Paulo: FGV, 2018.

DEZAN, Sandro Lucio. A Juridicidade do Estado-Administração na Concretização de Políticas Públicas de Saúde: Um Método para a Justificação da Eficácia Horizontal dos Direitos Fundamentais. Brasília: Revista A\&C, 2016. Disponível em: <http://abre.ai/aM56>. Acessado em: 15 de fevereiro de 2020. 
Eficácia Indireta para Além do Patrimônio. Curitiba: Uni Curitiba, 2018. Disponível em: <http://abre.ai/aM55>. Acessado em: 15 de fevereiro de 2020.

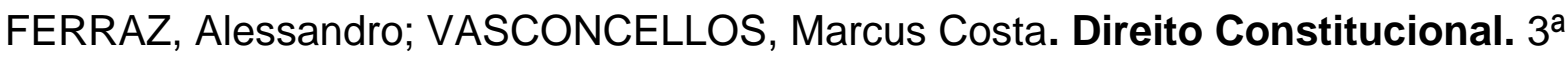

Ed. São Paulo Rideel, 2013.

GIACOBBO, Guilherme Estima; HERMANY, Ricardo. Democracia Representativa e Crise de Legitimidade: O Potencial da Subsidiariedade no Fortalecimento da Democracia Administrativa. Santa Cruz do Sul: UNISC, 2016. Disponível em: $<$ https://online.unisc.br/acadnet/anais/index.php/sidspp/article/view/15854>. Acessado em: 18 de fevereiro de 2020.

KUNRATH, Yasmine Coelho. Eficácia dos Direitos Fundamentais. Porto Velho: Saberes da Amazônia, 2016. Disponível em: <http://abre.ai/aM53>. Acessado em: 15 de fevereiro de 2020.

LAKATOS, Eva Maria; MARCONI, Marina de Andrade. Como Elaborar Projetos de Pesquisa. São Paulo: Editora Atlas, 2007.

Como Elaborar Projetos de Pesquisa. São Paulo: Editora Atlas, 2010.

LIMA, Adriana Almeida. A Atuação do IPAAM na Gestão Ambiental e Aplicação da Lei Delegada N.ㅇ 102, de 18 de Maio de 2.007, de Acordo com os Aspectos Técnicos que Determinam o Princípio da Precaução e Eficiência com Análise da Eficácia e da Efetividade IPAAM. Manaus: UEA, 2016. Disponível em:

<http://abre.ai/aM5Z>. Acessado em: 15 de fevereiro de 2020.

MARINONI, Luiz Guilherme; MITIDIERO, Daniel; SARLET, Ingo Wolfgang. Curso de Direito Constitucional. 8ª Ed. São Paulo: Saraiva, 2019.

MARMELSTEIN, George. A Eficácia Incompleta das Normas

Constitucionais: Desfazendo um Mal-Entendido sobre o Parâmetro Normativo das Omissões Inconstitucionais. Blumenau: Revista Jurídica, 2015. Disponível em: <http://abre.ai/aM5X>. Acessado em: 15 de fevereiro de 2020.

OLIVEIRA, Edmundo Alves de. Breves Anotações sobre as Ações

Afirmativas: Conceito, Abrangência e o Princípio da Igualdade. São Paulo: Âmbito Jurídico, 2017. Disponível em: <http://abre.ai/aM5W>. Acessado em: 15 de fevereiro de 2020.

PEREIRA, Cynthia Nóbrega. A Eficácia Horizontal das Garantias Fundamentais. Fortaleza: ESMEC, 2009. Disponível em: <http://abre.ai/aM5V>. Acessado em: 15 de fevereiro de 2020.

RESCHKE, Ana Paula Goldani Martinotto. A Eficácia do Direito Fundamental de Acesso à Justiça pela Efetividade do Direito de Razoável Duração do

Processo. Santa Cruz do Sul: UNISC, 2017. Disponível em: <http://abre.ai/aM5U>. Acessado em: 15 de fevereiro de 2020.

RODRIGUES, Rosiane. Para Pensar Diferente: Cidadania, Igualdades e Direitos. São Paulo: Moderna, 2016.

SARLET, Ingo Wolfgang. A Eficácia dos Direitos Fundamentais: Uma Teoria Geral dos Direitos Fundamentais na Perspectiva Constitucional. 13를 Ed. São Paulo: Livraria do Advogado, 2018.

STRECK, Lenio Luiz. Jurisdição Constitucional. 6ª Ed. São Paulo: Editora Forense, 2019. 
VASCONCELOS, Claudivina Campos. Violência Doméstica: A Aplicabilidade e Eficácia das Medidas Protetivas como Instrumento de Prevenção e Combate à Reincidência na Comarca de Barra do Garças-MT. São Paulo: Revista Direito em Debate, 2018. Disponível em: <http://abre.ai/aM5S>. Acessado em: 15 de fevereiro de 2020. 